\title{
Can carbonic acid protonate biological bases? Support from base protonation in methanol solvent.
}

\author{
Daniel Aminov ${ }^{1}$, Dina Pines ${ }^{1}$, Philip M. Kiefer ${ }^{2}$, Snehasis Daschakraborty ${ }^{2}$, \\ James T. Hynes ${ }^{2,3, \#}$, and Ehud Pines ${ }^{1, *}$ \\ ${ }^{I}$ Department of Chemistry, Ben-Gurion University of the Negev, POB 653, Ber Sheeva 84105, Israel. \\ ${ }^{2}$ Department of Chemistry and Biochemistry, University of Colorado, Boulder, CO 803090215, USA. \\ ${ }^{3}$ Chemistry Department, Ecole Normale Supérieure-PSL Research University, Sorbonne Universités- \\ UPMC University, Paris 06, CNRS UMR 8640 Pasteur, 24 rue Lhomond, 75005 Paris, France.
}

\begin{abstract}
In separate contributions, we have focussed on demonstrating that carbonic acid (CA) - historically considered too unstable to be a viable protonating agent - is able to protonate several types of $\mathrm{pH}$ indicators while behaving as a regular, moderately strong, carboxylic acid. Together with the experimental support we found for considering CA as a regular carboxylic acid are theoretical calculations demonstrating CA's ability to protonate methylamine within $25 \mathrm{fs}$ when forming with it a contact reactive complex. Here we briefly discuss a further aspect of this focus, involving the measurement of the lifetime and $\mathrm{pK}_{\mathrm{a}}$ of $\mathrm{CA}$ in pure methanol. The lifetime in methanol was found to be about 12-fold longer than in water, showing that the decomposition reaction of $\mathrm{CA}$ is solventdependent. The $\mathrm{pK}_{\mathrm{a}}$ change upon transferring CA from water to methanol was found to be $4.7 \pm 0.1 \mathrm{pK}_{\mathrm{a}}$ units, changing from $3.49 \pm 0.03$ to $8.16 \pm$ 0.05: this change is similar to the $\mathrm{pK}_{\mathrm{a}}$ change observed for common stable carboxylic acids when these are transferred from water to methanol. These results add further support of our earlier proposal that CA can be an important protonating agent of biological bases in the blood plasma.
\end{abstract}

This study is related to the question of whether Carbonic Acid's $\left(\mathrm{H}_{2} \mathrm{CO}_{3}, \mathrm{CA}\right)$ instability with respect to its decomposition to $\mathrm{H}_{2} \mathrm{O}$ and $\mathrm{CO}_{2}$ rules out, as is often thought, its chemical reactivity as a moderately strong Brønsted acid of considerable protonation ability. Previously, we have been able to demonstrate that, when encountering an indicator base molecule $\mathrm{B}, \mathrm{CA}$ does not break down to $\mathrm{H}_{2} \mathrm{O}$ and $\mathrm{CO}_{2}$ before protonating an acid-base indicator molecule in either of two ways. The first way is by contact protonation in the reaction $\mathrm{H}_{2} \mathrm{CO}_{3}+\mathrm{B} \rightleftarrows\left[\mathrm{B}^{\cdots} \mathrm{H}_{2} \mathrm{CO}_{3}\right]_{\mathrm{a}} \rightleftarrows \mathrm{HCO}_{3}{ }^{-}+\mathrm{H}^{+} \mathrm{B}$, while the second, indirect, way is by the reaction $\mathrm{H}_{2} \mathrm{CO}_{3}+\mathrm{B} \rightleftarrows[\mathrm{H}]^{+}{ }_{\text {aq }}+\mathrm{HCO}_{3}{ }^{-}+\mathrm{B} \rightleftarrows \mathrm{HCO}_{3}^{-}+\mathrm{H}^{+} \mathrm{B}$, where $[\mathrm{H}]^{+}$aq is the hydrated proton in the water solvent and $\mathrm{B}$ is the indicator molecule undergoing reversible protonation. B may be charged or uncharged [1]. We have found that CA behaves in all the situations studied by us, both experimentally $[2,3]$ and theoretically $[4,5]$, as an ordinary

\#,*Corresponding authors: chynes43@gmail.com; epines@bgu.ac.il 
carboxylic acid exhibiting efficient protonation capabilities in accordance with its considerable acidity somewhat greater than that of formic acid and lactic acid [3].

The ability of CA to protonate bases was further supported by Car-Parrinello ab initio molecular dynamics calculations of contact protonation of methylamine by $\mathrm{CA}$ in aqeuous solution [4, 5], Fig. 1. The results show an ultrafast proton transfer from $\mathrm{CA}$ to methylamine, a process allowed by the Mulliken CT electronic communication between the acid and the base. An additional computational study not yet published indicates a protonation reaction that is almost as fast as in the contact protonation case when one water molecule bridges CA and the base molecule; this is also a reaction which occurs without CA decomposition [6].
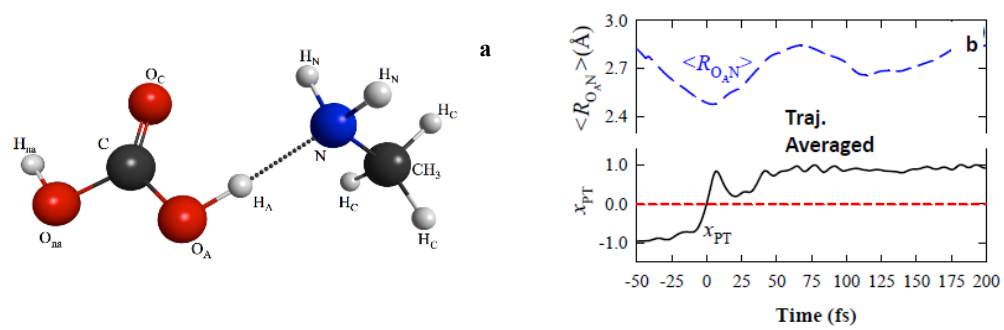

Fig 1. (a) The reactive H-bonding complex between CA and methylamine. For color-coding and the location of the various atoms see Ref. [4]. (b) Ab initio molecular dynamics results for proton transfer when complex immersed in aqueous solution [4]. Dashed blue line is the $\mathrm{O}_{\mathrm{A}}-\mathrm{N}$ H-bond separation ROAN versus time. Solid line is the 10 trajectory-averaged normalized proton coordinate, $\chi_{\mathrm{PT}}$, defined as the difference of the $\mathrm{O}_{\mathrm{A}} \mathrm{H}_{\mathrm{A}}$ and $\mathrm{H}_{\mathrm{AN}}$ stretch coordinates. The time $\mathrm{t}=0$ is set for $\chi_{\mathrm{PT}}=0$, the middle point in the proton coordinate when the proton is transferred from the oxygen to the nitrogen atom. The red dashed line indicates $\chi_{\mathrm{PT}}=0$.

Here we discuss our further substantiation of this important suggestion - that CA behaves as an ordinary carboxylic acid exhibiting efficient protonation capabilities in accordance with its considerable acidity - by measuring the $\mathrm{pK}_{\mathrm{a}}$ of CA in pure methanol. In this nonaqueous solvent, the lifetime of CA increases 12 -fold compared to the water solvent case ( $700 \mathrm{~ms}$ compared to $60 \mathrm{~ms}$ in water), and CA is able to protonate the dinitrophenol anion, a $\mathrm{pH}$ indicator molecule $\left(\mathrm{pK}_{\mathrm{a}}(\right.$ methanol $)=7.86$ [7] $)$; such protonation is a key feature allowing experimental study [1]. This observation may be important to the reactivity of $\mathrm{CA}$ in partially non-aqueous physiological environments, where based on our measurements in methanol, the lifetime of CA should be much longer than in water while the acid remains fully reactive.

In the experimental part of our study [1], we used the following stopped-flow apparatus shown in Fig. 2 for our aqueous solution CA studies. The $\mathrm{pK}_{\mathrm{a}}$ of $\mathrm{CA}$ in aqueous solutions was found to be $=3.49 \pm 0.03$ at $20^{\circ} \mathrm{C}$ and $3.59 \pm 0.03$ at $37^{\circ} \mathrm{C}$. We have used the same apparatus and procedure to study CA in methanol solvent. It is found that CA's $\mathrm{pK}_{\mathrm{a}}$ increased in methanol to $8.16 \pm 0.05$ and to $7.97 \pm 0.05$ at $20^{\circ} \mathrm{C}$ and $37^{\circ} \mathrm{C}$ respectively. These CA changes as a function of temperature and solvent are similar to that of acetic and formic acids - two ordinary stable carboxylic acids [7, 8] - in similar conditions. In particular, formic acid has a $\mathrm{pK}_{\mathrm{a}}$ comparable to that of $\mathrm{CA}, \mathrm{pK}_{\mathrm{a}}=3.75$, and exhibits an almost identical solvent dependence at $20^{\circ} \mathrm{C}, \Delta \mathrm{pK}_{\mathrm{a}}=\mathrm{pK}_{\mathrm{a}}($ methanol $)-\mathrm{pK}_{\mathrm{a}}$ (water) $=4.7 \pm$ $0.1 \mathrm{pK}_{\mathrm{a}}$ units $[7,8]$. The lifetime of $\mathrm{CA}$ for its decomposition to $\mathrm{H}_{2} \mathrm{O}$ and $\mathrm{CO}_{2}$ was found to be solvent-dependent, as discussed above. This observation is consistent with calculations by Loerting et al. showing that isolated $\mathrm{CA}$ is a stable molecule, and that its breakdown to $\mathrm{H}_{2} \mathrm{O}$ and $\mathrm{CO}_{2}$ is catalyzed by hydroxylic solvents like water on the sub-second timescale [9]: this is more than 10 orders of magnitude slower than the contact protonation by $\mathrm{CA}$ reported here and in ref. [4]. 

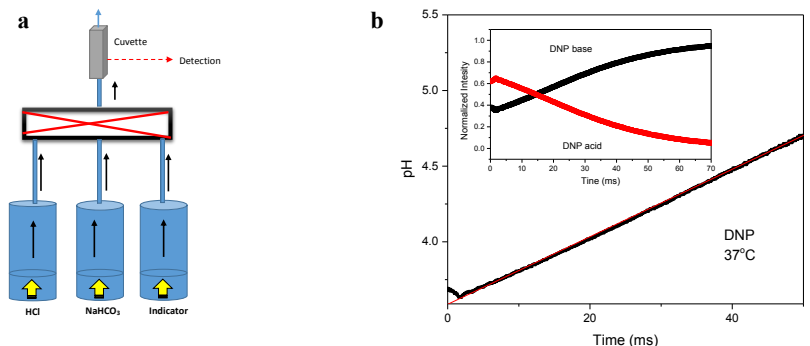

Fig. 2. (a) A stopped-flow setup for determination of carbonic acid (CA) acidity and lifetime while it spontaneously decomposes to $\mathrm{H}_{2} \mathrm{O}$ and $\mathrm{CO}_{2}$ [1]. CA is generated by rapid acidification of bicarbonate $\mathrm{HCO}_{3}{ }^{-}$by $\mathrm{HCl}$ in the water mixtures case [5] and by $\mathrm{HClO}_{4}$ in the methanol mixtures, then reacted in the same chamber with an acid-base indicator, either dinitrophenol (DNP) or methyl orange (MO) both having a comparable $\mathrm{pK}_{\mathrm{a}}$ to $\mathrm{CA}$ in water; $\mathrm{pK}_{\mathrm{a}}(\mathrm{MO})=3.46$ and $\mathrm{pK}_{\mathrm{a}}(\mathrm{DNP})=4.07$ at $20^{\circ} \mathrm{C}$ and in methanol for DNP $\mathrm{pK}_{\mathrm{a}}=7.86$. (b) $\mathrm{pH}$ versus time plot using DNP as the acid-base $\mathrm{pH}$ indicator. Inset: The absorption change in the concentration of the base (black line) and acid (red line) forms of the DNP $\mathrm{pH}$ indicator versus time measured in water. The $\mathrm{pH}$ was found by taking the ratio of the base to acid concentrations calculated from the absorbance data using the Beer-Lambert law. The lifetime of $\mathrm{CA}$ is found from the time dependence of the solution $\mathrm{pH}$ which changes as the decomposition reaction of CA progresses and de-acidifies the solution by removing CA from the solution. The $\mathrm{pK}_{\mathrm{a}}$ of $\mathrm{CA}$ is found by extrapolating the almost linear dependence of the solution $\mathrm{pH}$ vs. time to time zero at which the $\mathrm{pK}_{\mathrm{a}}$ of $\mathrm{CA}$ is equal to the $\mathrm{pH}$ because the concentration of the bicarbonate anion at time zero was set to be equal to the concentration of CA (the HendersonHasselbalch equation [10]).

In summary, we find the $\mathrm{pK}_{\mathrm{a}}$ and the lifetime of CA in methanol to be considerably larger and longer respectively than in water, and that the effect on its transfer from water to methanol is very similar to the effect observed for this same solvent transfer for regular stable carboxylic acids such as acetic acid. These results bring additional evidence for CA behaving like a regular carboxylic acid.

This work has been supported by the NIHPO1000125420 (JTH, EP) and the ISF1587/16 (EP) Grants.

1. D. Aminov, D. Pines, P. M. Kiefer, S. Daschakraborty, J. T. Hynes, E. Pines, (In preparation)

2. K. Adamczyk, M. Premont-Schwarz, D. Pines, E. Pines, E. T. J. Nibbering, Science, 326, 1690 (2009)

3. D. Pines, J. Ditkovich, T. Mukra, Y. Miller, P. M. Kiefer, S. Daschakraborty, J. T. Hynes, E. Pines, J. Phys. Chem. B 120, 2440 (2016)

4. S. Daschakraborty, P. M. Kiefer, Y. Miller, Y. Motro, D. Pines, E. Pines, J. T. Hynes, J. Phys. Chem. B 120, 2271 (2016)

5. S. Daschakraborty, P. M. Kiefer, Y. Miller, Y. Motro, D. Pines, E. Pines, J. T. Hynes, J. Phys. Chem. B 120, 2281 (2016)

6. S. Daschakraborty, P. M. Kiefer, D. Pines, E. Pines, J. T. Hynes, (In preparation)

7. F. Rived, M. Roses, E. Bosch, Anal. Chim. Act. 374, 309 (1998)

8. R. A. Robinson and R. H. Stokes, Electrolyte solutions (Academic Press, New York, 1959)

9. T. Loerting, C. Tautermann, R. T. Kroemer, I. I. Kohl, A. Hallbrucker, E. Mayer, K. R. Liedl, Angew. Chem. Intern. Ed. 39, 891 (2000)

10. K. A. Hasselbalch, Biochem. Z. 78, 112 (1917) 